\title{
YOĞUN BAKIMDA VASKÜLER GIRIŞiMSEL UYGULAMALAR VE AKCIĞER DESTEK CIHAZLARI
}

\section{INVASIVE VASCULAR INTERVENTIONS AND LUNG ASSIST DEVICES IN INTENSIVE CARE UNITS}

\author{
Maruf Şanlı \\ Gaziantep Üniversitesi Tıp Fakültesi Göğüs Cerrahisi Anabilim Dalı, Gaziantep, Türkiye \\ e-mail: sanlimaruf@yahoo.com \\ DOI:10.5152/tcb.2014.026
}

Özet

Yoğun bakımda yatması gereken hastalarda takip ve tedavi amaçlı kullanılan girişimsel uygulamalar neredeyse kaçınımazdır. Bu yazıda yoğun bakım ünitelerinde sıklıkla kullanılan vasküler invaziv girişimler ele alınacak, bunun yanında akciğer destek cihazlarından bahsedilecektir.

Anahtar kelimeler: Santral Venöz Kateterizasyon, Arteryel Kateterizasyon, ECMO, Novalung

\section{ARTER KATETERIZASYONU}

Yoğun bakımda yatan genel durumu kritk hastalarda hemodinamik ölçümlerin çoğunlukla invaziv olarak yapılması gerekir.

Arter kanulasyonu ile arter basıncının sürekli monitorizasyonu sağlanarak, ani basınç değişiklikleri saptanır ve bu sayede kritik tedaviler uygulanabilir. Ölçümün doğru olması için uygun arter hattı seçilmeli, sistemdeki hava uzaklaştııımalı, sistem sıfırlanmalı ve transduser seviyesi doğru ayarlanmalıdır (1). Yoğun bakımda kullanılan arter kateterizasyonu endikasyonları ve komplikasyonları Tablo 1 ve 2 de verilmiştir. Lokal enfeksiyonun olduğu bölgeler veya proksimalde obstrüksiyonun olduğu arterler, girişim için uygun değildir. Kuagulopatisi olan olgularda arter kateterizasyonu kontrendikedir.

Arter kanulasyonu için en sık olarak radial arter tercih edilmekle birlikte brakial, aksiller, femoral, dorsalis pedis veya posterior tibial arterler kullanılabilir. Nadiren, aksiller veya yeni doğanlarda umblikal arter kullanılabilir. Perkütan giriş çoğu kez başarılıdır, ancak nadiren "cut-down" gerekebilir (2).

Perkütan giriş sırasında direk kanulasyon yapılabileceği gibi Seldinger tekniği de kullanılabilir. Seldinger

\begin{abstract}
Interventional applications used for follow-up and therapeutic purposes are almost inevitable in intensive care unit patients. In this article, invasive vascular interventions, as well as lung assist devices frequently used in intensive care units, will be discussed.
\end{abstract}

Key words: Central Venous Catheterization, Arterial Catheterization, ECMO, Novalung

teknikte artere bir ponksiyon iğnesi ile girilir. İğnenin içinden bir kılavuz tel geçirildikten sonra iğne çıkarılır. Kılavuz telin üzerinden kateter, arter içerisine ilerletilir.

\section{Radial Arter Kateterizasyonu}

Arteryel kateterizasyonda hem çocuk hem de yetişkin hastalarda, anatomik olarak kolay kanülasyonu ve düşük komplikasyon oranları nedeniyle en sık radial arter kullanilır. Radial arter kateterizasyonu sonrası görülebilen el iskemisi riski nedeniyle, işlemden önce Allen testi ile eldeki sirkülasyonun durumu değerlendirilebilir. Allen testinde, hastanın kolu yukarıda tutularak venöz kan boşaltılır. Radial ve ulnar arterler parmakla komprese edilirek, el aşağı sarkıtııı. Ulnar artere yapılan bası kaldırılır. Altı saniye içinde soluklaşan elin renginin düzelmesi, ulnar arterin açık olduğunu ve palmar arkusun yeterli olduğunu gösterir. Kızarıklığın 7-15 saniyeden uzun sürede ortaya çıkması ise ulnar arkus doluşunun yetersiz olduğunu gösterir (2). Allen testi ile elin dolaşımının radial artere bağlı olduğu kararına varılırsa kanülasyon için ulnar arter seçilebilir.

Radial arter kanülasyonu için bilek, dorsal yüzüne bir rulo yerleştirilerek dorsifleksiyona getirilir ve kol tahtasına sabitlenir. Arter kanulasyonu için gerekli mal- 
zemeler hazırlanır (Resim 1). Cilt temizliği sağlandıktan sonra arter üzeri bölgeye lokal anestezi uygulanır. Radial arter palpe edilir ve arkasına enjektör takılmış $20 \mathrm{G}$ anjioket ile 30 derecelik açı verilerek artere girilir. Artere girildiğinde iğne ile cilt arasındaki açı 10 dereceye indirilir ve iğnenin haznesindeki kan gözlenerek, anjioket, iğnenin üzerinden arterin içine itilir. Eğer iğnenin arkasından kan damlaması durmuşsa arterin arka duvarının delindiği düşünülmelidir. Bu durumda iğne anjioketin içinden çıkarılır, kan yeniden görülünceye kadar anjioket, yavaşça geri çekilir. Kan yeniden damlamaya başladığında ise anjioket, arterin içine yavaşça ilerletilir. Anjioketin sorunsuz olarak iğne üzerinden damar içine kaydırıldığı durumda ise, iğne geri çekilir ve anjioket, bağlantı sistemine bağlanarak, emniyetli bir şekilde tespit edilir (Resim 2). Bağlantı sistemleri genellikle basınç hatları, üç yollu musluklar, sürekli yıkama sistemleri ve transduser içerir. Modern transduserler sık tekrarlayan kalibrasyon ve sıfır ayarının neden olduğu zorlukları önlerler. Kateterin yerleştirilmesinden sonra dorsifleksiyon pozisyonu sonlandırılır. Bileğin uzun süre bu pozisyonda kalması halinde, gerilmeye bağı olarak medyan sinir hasarı gelişebilir.

Kateter lümeninin tıkanmasına bağlı olarak trombüs oluşumunu önlemek ve kateterden daha uzun süre yararlanılmasını sağlamak için, kateter, heparinize bir solusyon ile (1-3 ml/saat) sürekli olarak yıkanmalıdır. Bu solüsyon $\mathrm{NaCl}$ solüsyonuna $1 \mathrm{U} / 1 \mathrm{ml}$ olacak şekilde heparin ilave edilerek hazırlanır (2).

Sık görülmemekle birlikte kateterin tromboza bağlı tıkanması, dijital emboli, elde iskemi, hematom, psödoanevrizma, sinir hasarı ve enfeksiyon gibi komplikasyonlar görülebilir. Kateter kalış süresi uzadıkça, komplikasyon riski artmaktadır. Ayrıca kanülün çıkarılmasından sonra vazospazma bağı geçici oklüzyon intimali olabilir (3).

\section{Radial Arter Dışındaki Arterlerin Kateterizasyonu}

Brakial arter, antekubital fossada, biseps tendonunun medyalinde ve medyan sinire çok yakın olarak seyreder. Brakial ve aksiller arterler gerektiği durumlarda kanule edilebilir.

İskemik komplikasyon oranının yüksek olması nedeniyle femoral arterin kanülasyonu, nadiren (genellikle diğer arterler kanüle edilemediği zaman) tercih edilir. Periferik vasküler hastalığı olanlarda gözlenebilecek olan aortik obstüksiyon, femoral arterdeki basıncı azaltabilir. Yine bu hastalarda femoral arterde varolabilen aterom plakları, emboli ve distal iskemi riski oluşturur (3).

Dorsalis pedis ve posterior tibial arter, elde olduğu gibi bir arteryel ark oluşturarak, ayağı besler. Dorsalis

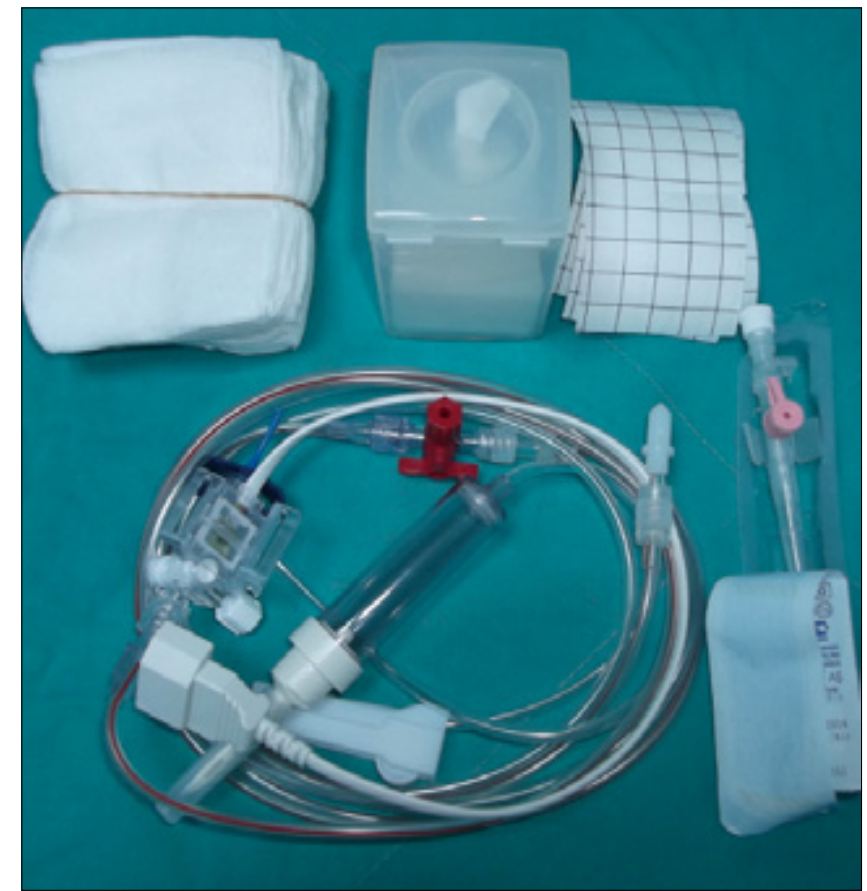

Resim 1. Radial arter kanulasyonu için gerekli malzemeler

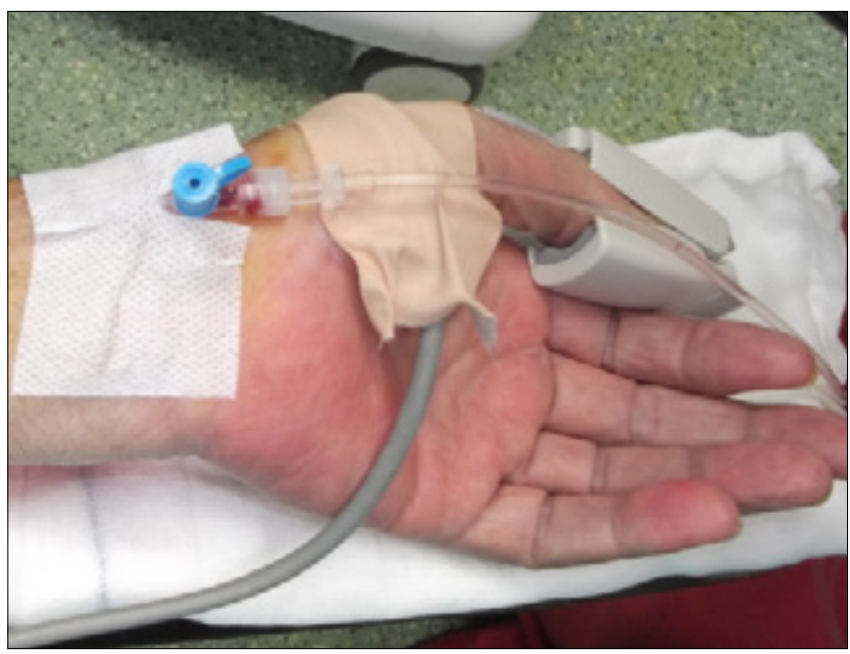

Resim 2. Radial arter kateterizasyonu gerçekleştirilerek, aretr hattına bağlanmış durumda görülüyor.

Tablo 1. Yoğun bakımda kullanılan arteriyel kateterizasyon endikasyonları

Sık arteryel kan gazları analizi gereksinimi

Hipovolemik, kardiyojenik veya septik şok ya da multi organ yetersizliği

Masif travma

İnotrop veya intraaortik balon kullanımı gerekliliği

Sık kan örneği alınması gerekliliği

Arteriyel basıncın noninvaziv olarak ölçümünün mümkün olamaması (Morbid obesite) 
pedis, diğer arterler kanüle edilemediğinde seçilebilecek, nisbeten daha küçük çaplı bir arterdir. Sistolik arter basıncı radial arter veya brakial arterden 10-20 $\mathrm{mmHg}$ yüksek, diastolik basınç ise $15-20 \mathrm{mmHg}$ daha düşüktür.

\section{SANTRAL VENÖZ KATETERIZASYON (SVK)}

Santral Venöz Kateterizasyon (SVK) yoğun bakım ünitelerinde en sık uygulanan girişimsel uygulamalardan biridir. Yüksek ozmolariteli solüsyonların verilmesi, santral venöz basınç ölçümü, hemodiyaliz veya hemofiltrasyon uygulanması, venöz kan gazları analizi için gerekli kan örneğinin alınması ve diğer metabolik parametrelerin analizi amacıyla SVK uygulanır (Tablo 3) (4).

Santral venöz girişim yeri, hasta için en uygun olan ve hekimin deneyiminin iyi olduğu yöntem doğrultusunda belirlenir (5). Kateter ucunun en uygun yerleşim yeri vena kava superiorun atrium girişinin 3-5 cm proksimalidir.

SVK için kullanılabilecek venler; subklaviyan ven, internal jugular ven (IJJV), eksternal jugular ven, kol venleri (antekübital ven, bazilik ven, sefalik ven) ve femoral vendir.

SVK sırasında arteryel girişler konusunda dikkatli olunmalıdır. Kanın pulsatil olup-olmadığı değerlendirilmeli, gerekirse kan gazı analizi yapılmalıdır.

Santral yerleşimli kateterler uzun süre damar içinde kalırsa, tromboza veya septik embolilere yol açabilir (Tablo 4). Bu nedenle endikasyon dikkatlice değerlendirilmeli ve hastanın durumu düzeldiğinde mümkün olan en kısa zamanda çıkarımalıdır. Santral venöz kateterin 3-4 haftadan daha uzun sürecek kullanımları için, kaflı-tünelli kateterler veya perkütan intravenöz port tercih edilmelidir.

Santral venöz kateterizasyonda kullanılan kateter setlerinin içinde; yapısı, uzunluğu, çapı, lümen sayısı gibi özellikleri farklı olabilen kateter ve yine uzunluğu, çapı, şekli değişik olan ponksiyon kanülünün yanısıra, uygulanan tekniğe göre değişen farklı malzemeler bulunabilir (Resim 3). Seldinger (indirekt) teknik kullanılan setlerde ayrıca kılavuz $\mathrm{J}$ tel, uygun çaplarda dilatörler, enjektör, bistüri bulunur. Bu setler, erişkin ve pediyatrik hastalarda kullanımı amacıyla değişik boyutta (French-Fr-) paketlenmiş olarak piyasada bulunmaktadır. Kateter seçimi; hastanın yaşı, ponksiyon yapılacak yer, kateter yerleştirme amacı ve uygulayıcının deneyimine göre yapılmaktadır (5). Erişkin hastalarda çoğunlukla kateter seti, 7 Fr olarak tercih edilir.

\section{İnternal Juguler Ven Kateterizasyonu}

İnternal juguler ven kanulasyonu, subklavian ven girişine göre daha kolay uygulanan ve daha az komp-
Tablo 2. Yoğun bakımda kullanılan arteriyel kateterizasyon komplikasyonları

Enfeksiyon

Hemoraji

Tromboz ve distal iskemi

Cilt nekrozu

Embolizasyon

Hematom ve nörolojik hasar

Psödoanevrizma -arteriovenöz fistül

Tablo 3. Yoğun bakımda kullanılan santral venöz kateterizasyon endikasyonları

Hipovolemik şok

Kardiyopulmoner resusitasyon

Santral venöz basınç ölçümü

Pulmoner arter kateterizasyonu

Uzun dönem total parenteral beslenme

Hemodiyaliz-hemofiltrasyon-plazmaferez

Acil transvenöz kalp pili

Preoperatif hazırlık

Radyolojik girişimler

İritan veya vazoaktif ilaç uygulamaları

Tablo 4. Yoğun bakımda kullanılan santral venöz kateterizasyon komplikasyonları

Venöz tromboz, Kateter embolisi, Hava embolisi, Hematom, Kateter enfeksiyonu, Endokardit, Damar duvarı hasarı, Aritmi, Pnömotoraks, Hemotoraks, Kateter giriş yeri enfeksiyonu

likasyonlu bir yöntemdir. Sağ atriuma kısa-düz bir yol oluşturması nedeniyle kateterin ucu hemen daima ya sağ atriyumda ya da superior vena kava'dadır.

İşlem için uygulayıcı hastanın baş kısmındadır. Sırt üstü yatar pozisyondaki hastanın başı, omuz altına yastık yerleştirilerek geriye doğru düşürülür ve hastanın başı uygulama yapılacak yerin ters tarafına doğru çevrilir. Hava embolisi riski nedeniyle hastaya verilen 15 derecelik trendelenburg poziyonu, aynı zamanda venöz distansiyonu sağlayarak, girişi kolaylaştırır. Juguler venöz dolgunluğunu artırmanın diğer bir yolu, karaciğer üzerine baskı yapmaktır.

Girişim için boyun steril bir şekilde örtülür ve giriş bölgesine lokal anestezi uygulanır. Öncelikle sternokleidomastoid (SKM) kasının sternal ve klavikular başlarının klavikulanın üzerinde oluşturduğu üçgen 
belirlenir. Girişim, SKM'nin iki kasının ve klavikulanın yaptığı, açıklığı aşağı bakan üçgenin tepesinden yapılır (6). Karotis nabzı girişim yapılacak yerin $1-2 \mathrm{~cm}$. medialinde sol el ile palpe edilir. Sağ elde tutulan enjektöre bağlı ponksiyon iğnesi ile, üçgenin tepesinden, 45 derecelik bir açı ile aynı taraftaki meme ucuna bakacak şekilde girilir (Kadınlarda meme başının lokalizasyonu değişeceğinden, erkekte olması gereken yer tahmin edilir). İğne, aspire edilerek ilerletilir ve $3-5 \mathrm{~cm}$ içinde IJJV ponksiyonu sağlanır. Lümene girildikten sonra, enjektörden ayrılan ponksiyon iğnesinin arkasından kılavuz J tel, $15-20 \mathrm{~cm}$ kadar ilerletilir. Bu işlem sırasında ponksiyon iğnesinin sabit tutulması çok önemlidir. Tel ilerletilirken perforasyon riski nedeniyle dikkatli davranılmalıdır (Telin ilerlemesinde herhangi bir zorlama söz konusu olursa, tel çıkarılıp, yeniden kan aspirasyonu sağlanır). Daha sonra kılavuz tel yerinde bırakılarak, iğne çıkarılır. Kılavuz telin cilde giriş yeri, 11 no. bistüri ucu ile dilatörün girmesine izin verecek şekilde kesilir. Tel üzerinden önce dilatör ilerletilir. Kateterin geçişini sağlayacak yeterli genişlik sağlandıktan sonra dilatör geri çekilir. Tel üzerinden kateter gönderilir. Kateterin kılavuz tel üzerinden gönderilmesi sırasında, kateter ucu cilt seviyesinde iken, kılavuz telin kateterden çıktığı gözlenmelidir. Kılavuz tel sabitken kateter kaydırılarak, vene yerleştirilir ve kılavuz tel geri çekilir. Kanın serbest bir şekilde kateterden alınabildiği gözlenmelidir. Kateter cilde dikilir ve giriş yeri steril bir şekilde kapatıı.ır.

Kanülasyon için boyunda ven trasesi üzerindeki herhangi bir yerden de girmek mümkündür. Hipovolemi ve işlem sırasında karotid artere yapılan aşırı parmak basısı nedeniyle ven lümenindeki daralma göz önünde bulundurulmalıdır. İşlemde başarısızlık söz konusu ise diğer taraf İJV girişimi yapılabilir. Ultrason rehberliği mekanik komplikasyonları azaltacaktır (6). İşlem sırasında artere giriş halinde doğrudan bası ile kanama kontrolü yapılabilir. Bu sırada oluşan hematom, sonraki denemelerin başarısız olmasına yol açabilir. Pnömotoraks oldukça nadirdir.

\section{Subklavian Ven Kateterizasyonu}

Enfeksiyon riskinin azlığı, baş hareketlerinden etkilenmemesi, hasta konforu, kateter bakımındaki kolaylıklar nedeniyle tercih edilmesine karşın, komplikasyon oranı daha yüksektir. Özellikle pıhtılaşma bozukluğu olan hastalarda, işlem sırasında arter girişi olması halinde arter kompresyonu zorluğu açısından, tercihen diğer giriş yolları kullanılmalıdır.

Hasta, omuzların ortasına konulan yuvarlak bir yastık ile 15-30 derecelik trendelenburg pozisyonunda, baş hafif karşı tarafa dönecek şekilde sırt üstü yatırıır. Uygulayııı girişimin yapılacağı omuz tara-

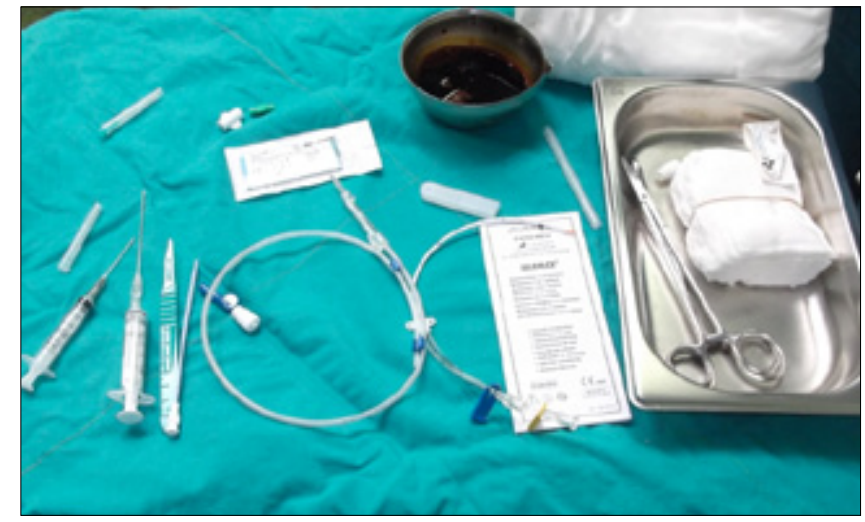

Resim 3. Santral venöz kateterizasyon için gerekli olan malzemeler.

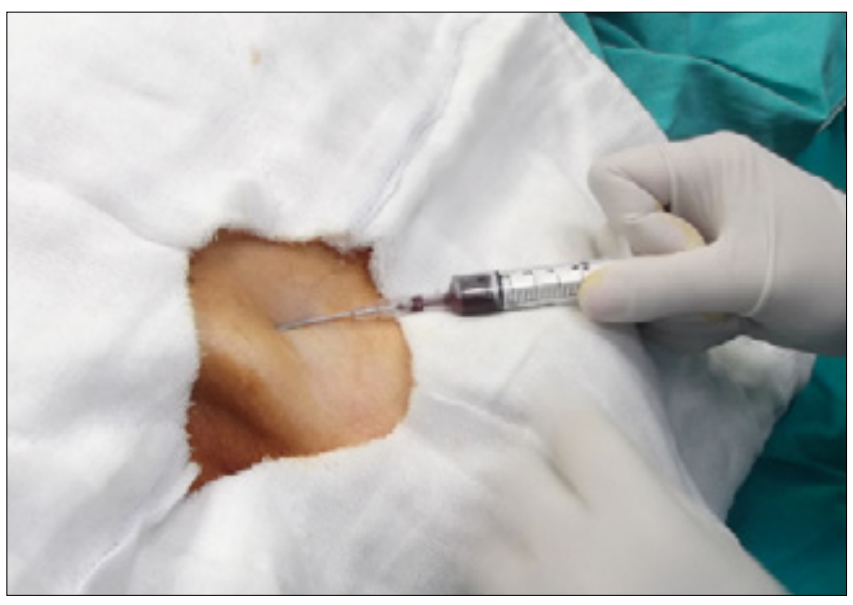

Resim 4. Subklavian ven ponksiyonu

fındadır. Kanülasyon bölgesi steril edilerek, uygun şekilde örtülür ve lokal anestezi uygulanır. Subklavian ven, klavikulanın medial bölümü altından seyreder. Klavikulanın orta noktası ve suprasternal çentik belirlenir. Enjektörün ucundaki ponksiyon iğnesi ile klavikula orta noktasının $1 \mathrm{~cm}$ altından cilde girilir (Resim 4). Cilde giriş noktası SKM kasın klavikular parçasının laterali gözetilerek te belirlenebilir. İğne, ucu suprasternal çentiğe (veya karşı omuza) bakacak şekilde, klavikula altından, aspirasyon ile kan gelişi oluncaya kadar ilerletilir. İğne, klavikulanın sternal ucunu geçmemeli ve klavikulanın altı planından ayrımamalıdır. Aksi takdirde iğne ucu, plevra ve akciğer hasarına yol açabilir. Kan gelince işlemler yukarıda anlatıldığı sıra ile yapılır (Resim 5). Ancak özellikle enjektörün ponksiyon iğnesinden ayrılması ve kılavuz telin iğneden geçirilmesi sırasında hava embolisi riskine karşı dikkatli davranılmalı, bu esnada yapılabiliyorsa hastanın nefesi tutturulmalıdır. Kılavuz telin ilerletilmesi sırasında zorlukla karşılaşılırsa, baş ve kola değişik pozisyonlar (kolun aşağı çekilmesi veya dışa açılması, başın aynı yöne çevrilmesi gibi) verilebilir. 
İşlem sırasında artere giriş söz konusu ise 5-10 dk.lık direk bası uygulanarak, kanama ve hematom oluşumu engellenir (7).

Perkütan giriş genellikle başarılı olur (Resim 6). Ancak son zamanlarda ultrason eşliğinde daha kolay girişimler mümkün olmaktadır. Göğüs tüpü bulunan hastalarda aynı taraftan girişim yapılması, işlem sırasındaki hemopnömotoraks riski açısından tercih edilmelidir. İşlem sonrası, özellikle de zor girişlerden sonra arka-ön akciğer grafisi ile toraks değerlendirilmelidir $(4,7)$. İşlem başarısızlığı halinde grafi değerlendirilmeden karşı taraf subklavian ven girişi denemesi yapılmamalıdır. Bilateral pnömotoraks ölüm ile sonuçlanabilir.

Subklavian ven kateterizasyonu sonucu erken dönemde boyunda hematom, kardiyak aritmi, hava embolisi, kateter embolisi, pnömotoraks, hemotoraks, duktus torasikus hasarı gelişebilirken, geç dönemde enfeksiyon, ven trombozu, kardiyak tamponad görülebilir. Kateter bazen internal juguler vene veya karşı subklavian vene yönelebilir.

\section{Femoral Ven Kateterizasyonu}

Femoral ven kanülasyonu, internal juguler veya subklavian ven kanülasyonuna göre bir takım avantajlara sahiptir. Anatominin palpasyonla saptanabilmesi, venöz veya arteryel kanamaların kontrolünün mümkün olması, pnömotoraks riskinin bulunmaması avantaj iken, perineye yakınlığı nedeni ile enfeksiyon riskinin fazla olması dezavantaj oluşturur (6).

Hasta sırt üstü pozisyonda yatırılır ve uyluğa hafif abduksiyon ve dış rotasyon yaptıriır. Kanulasyon bölgesi steril şartlarda hazırlanır. Simfizis pubis ve süperior-anterior iliak spina arasında seyreden inguinal ligamanın 1-2 cm altında, femoral arter palpe edilir. Femoral ven, arterin medialinde (VAN kuralı) ve artere paralel olarak uzanır. Giriş bölgesine lokal anestezi uygulanır. Sol el işaret ve orta parrmağı ile femoral arter sabitlenecek şekilde tutulurken, ponksiyon iğnesi $1 \mathrm{~cm}$ mediale batırilır. Femoral arter pulsasyonu olmayan hastalarda, anterior superior iliak çıkıntı ile pubik tuberkül arasındaki mesafenin 1/3 medial noktası, arter olarak belirlenir. İğne yukarı-içe doğru, cilt ile 20-30 derecelik açı yapacak şekilde, femoral venden aspirasyon ile kan gelinceye kadar ilerletilir. Kanın gelişi gözlendikten sonra işlemler yukarıda anlatıldığı sıra ile yapilır.

İşlem sırasında artere giriş gözlenebilir. Böyle bir durumda artere parmakla bası uygulanarak daha mediale ponksiyon yapılır.

Femoral ven, yoğun bakım hastalarında, yüksek başarı şansı ve düşük majör komplikasyon olasılığı nedeniyle özellikle diğer yöntemler için deneyimsiz

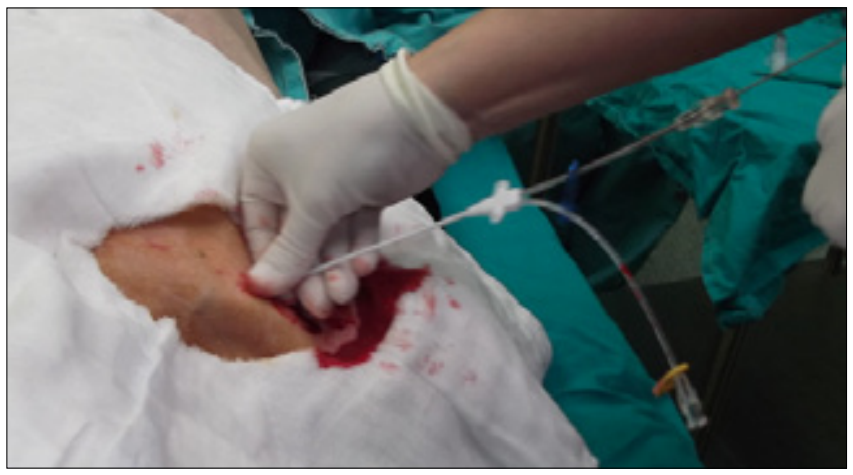

Resim 5. Subklavian ven kateterinin, kılavuz tel üzerinden kaydırılarak, ven içine ilerletilmesi.

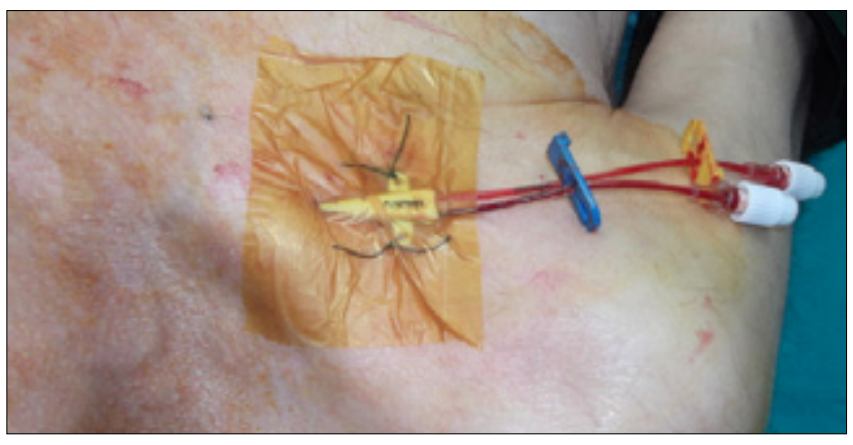

Resim 6. Çift lümenli santral ven kateteri, subklavian vene yerleştirilmiş olarak görülüyor.

olanların kullanabileceği, elverişli bir santral kateterizasyon yoludur $(4,6)$.

\section{Pulmoner Arter Swan-Ganz Kateterizasyonu}

Pulmoner artere kateter yerleştirilmesi ilk olarak 1964'de Bradley tarafından tarif edilmiş, Swan ve arkadaşları tarafından geliştirilerek, balonlu pulmoner arter kateterinin klinik uygulamaya girmesini sağlayarak yeni bir çığır açmıştır.

Pulmoner arter kateterizasyonu ile sol atrial basınç, pulmoner kapiller "wedge" basınç kardiak debi ve pulmoner arter basıncı ölçümleri yapılabilir. Aynı zamanda bu teknikle intrapulmoner şant fraksiyonu tahmin edilebilir. İntrapulmoner kateter, myokardit, kardiomyopati, pulmoner hipertansiyon, komplike konjenital kalp hastalıkları ile akut respiratuar distres sendromunda kullanım alanı bulmaktadır.

Bu kateterlerin perkütan yolla sağ juguler veya sol subklavian yoldan yerleştirilmesi tercih edilir, ancak femoral yoldan da yerleştirilmesi mümkündür. Kılavuz tel gönderilerek daha önce tarif edilen prosedürler ile kateter yerleştirilir. Tek yönlü valv kullanılarak, hava embolisi veya kanamayı engellemek mümkündür. Kateterde bulunan ilave fleksibl koruyucu körükler, yeni ölçümlerde kateterin tekrar steril bir şekilde yerleştirilmesini sağlar. Kateter sağ atriuma ilerletilir, 
balon karbondioksit ile şişirilir ve kan akımı ile pulmoner artere girmesi sağlanır. Kateterin pulmoner arterde olduğu basınç trasesi ile belirlenir. Pulmoner artere girişin başarısız olduğu durumlarda katetere floroskopi veya ekokardiografi ile gerekli pozisyon verilebilir (2).

\section{AKCIĞER DESTEK CIHAZLARI}

Yapay akciğerler için üç ana sınıflandırma vardır: Ekstrakorporeal, parakorporeal ve implante edilebilir cihazlar.

Ekstrakorporeal akciğer destek cihazları (Ekstrakorporeal Membran Oksijenatör -ECMO- ve Interventional Lung Assist -ILA-) sayesinde gaz değişimi, dışardan yapay bir akciğer sayesinde yapılır. Günümüzde, maksimum tıbbi tedaviye yanıt vermeyen solunum ve/veya kalp yetmezliği bulunan yenidoğan, çocuk ve erişkin hastalarda kullanılmaktadır

Parakorporeal yapay akciğer ile hastanın sağ kalbi bir pompa olarak kullanılmaktadır. Alet, farklı bağlanma modları kullanılarak pulmoner dolaşıma bağlanmaktadır.

İmplante edilebilir yapay akciğerler ise yapay solunum çalışmalarının nihai hedefidir. İlk intravasküler oksijenatör (iVOX), 1994 yılında uygulanmıştır. 2004 yılında, Almanyaıdan "highly integrated membrane oxygenatorĐ (HIMOX) adında ikinci bir implante edilebilir yapay akciğer tanıtımı yapıımıştır.

Bu yazıda ekstrakorporeal akciğer destek cihazları olan ECMO ve Novalung'tan bahsedeceğiz.

\section{Ekstrakorporeal Membran Oksijenatör (ECMO)}

Hem kardiyak hem de pulmoner destek sağlayan ECMO sistemi, bir santrifüj pompa, membran oksijenatör, giriş ve çıkış kanüller ve hatlardan oluşur (8). Hastadan gelen sistemik venöz kanın vücut dışarısına alınması, oksijenatör aracılı̆ıyla kandan karbondioksitin $\left(\mathrm{CO}_{2}\right)$ uzaklaştırıması ve oksijenin $\left(\mathrm{O}_{2}\right)$ verilmesi, yapay bir kalp görevi gören pompa yolu ile de kanın vücuda gönderilmesi ilkesiyle çalışır. Sistem, altta yatan patolojiyi düzeltmez ancak geçici bir yaşam destek görevi görür (9).

İki farklı teknikle ECMO kullanılabilir: Venoarteryel ve venovenöz. ECMO genellikle veno-arteryel olarak, hem kardiyak hem de pulmoner destek sağlamak amacı ile kullanılırken, kardiyak fonksiyonların yeterli olduğu durumlarda sadece pulmoner fonksiyonların desteklenmesi için veno-venöz olarak kullanılabilir (9). ECMO endikasyonları Tablo 5'te belirtilmiştir.

Venoarteryel tekniğinde, kanülasyon femoral arter ve femoral ven yoluyla ya da karotid arter ve juguler ven yoluyla yapılr. Venovenöz teknik kanülasyonu,

\section{Tablo 5. $X X X X X X X X X X X X X X X X X X X X X X X X X$}

ECMO endikasyonları, Persistan Pulmoner Hipertansiyon, Mekonyum Aspirasyonu, Respiratuvar Distres Sendromu, Konjenital Diyafragmatik Herni, Travma, Pnömoni, Kardiyomiyopati, miyokardit, Pulmoner emboli, Postoperatif konjenital kalp hastalıkları/kalp transplantasyonu

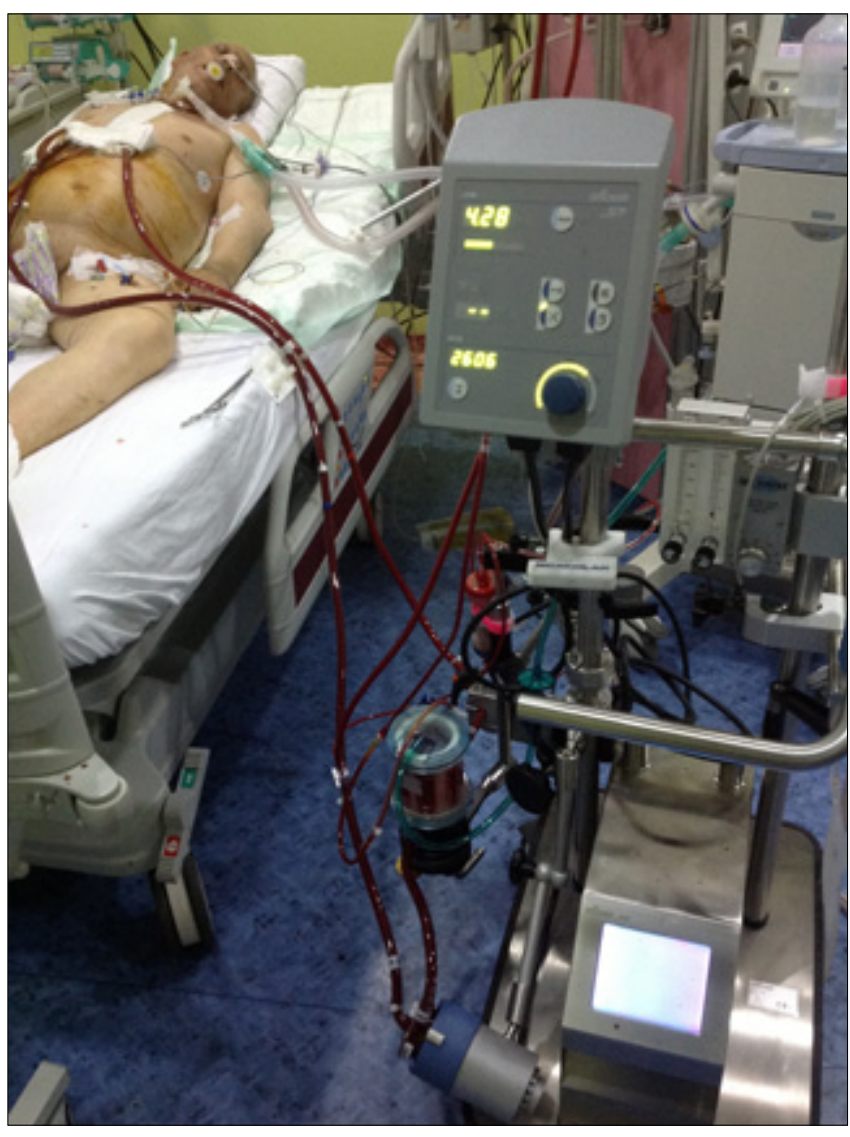

Resim 7. Hastaya bağlanmış halde bulunan ECMO cihazı.

her iki femoral venler veya femoral ven ve internal juguler ven olarak gerçekleştirilir (8); bir kanül arteriyel hat, diğeri venöz hat görevi görür. Hastada pulmoner hipertansiyon veya sağ kalp yetmezliği varsa venovenöz ECMO yeterli destek vermeyecektir.

Ekstrakorporeal Membran Oksijenatör (ECMO) uygulaması sistemik antikuagülasyon altında yapılır. ECMO'ya başlamadan önce hastaya ACT 180 - 200 sn. olacak şekilde heparinizasyon yapılır (10). Aşırı kanama olduğunda, kanama kontrol edilinceye kadar daha düşük ACT seviyeleri tolere edilebilir.

ECMO uygulamasında hasta kanüle edilir ve ECMO cihazından gelen hatlar, arada hiç hava kabarcığı kalmayacak şekilde birleştirir (Resim 7). Önce venöz hattaki klemp, sonra arterdeki klemp kaldırıır. Uygun akım hızına doğru yükselirken hesaplanan oksijen açılır. Yeterli bir pompa debisi ve perfüzyon için, 
dolaşımdaki kan volümünün yeterli olması gerekir. ECMO uygulaması sırasında, arteryel basınç, ortalama 50 - 70 mmHg civarında olacak şekilde, yeterli bir hemodinamik destek sağlanmalıdır.

ECMO kullanılan hastada arteryel ve venöz kan gazı, elektrolitler, albumin ve hemogram takip edilir. Daha iyi kapiller perfüzyonun sağlanması için htc $>30$ olmalıdır. Trombosit sayısı 100.000 ve üzerinde tutulur (10). ECMO desteği altında arteryel kan gazı parametreleri optimal olmalıdır. Venöz kan gazı ile de perfüzyonun yeterliliği değerlendirilir. ECMO desteği altında iken ventilator parametreleri PEEP 8-10 $\mathrm{cmH}_{2} \mathrm{O}$, solunum frekansı 4 - 6 /dk. ve paO2 $60 \mathrm{mmHg}$ sağlayacak şekilde ayarlanır (11).

Hastanın parenteral ve enteral beslenmesi ile yeterli kalori alımı sağlanmalıdır.

Diüretiklere dirençli oligüri, anüri, renal fonksiyon bozukluğu, elektrolit dengesizliği durumlarında ECMO sistemine ultrafiltrasyon/diyaliz uygulamaları eklenir.

ECMO desteği, hastanın kardiyopulmoner fonksiyonlarının düzelmesi için birkaç günden 1-2 haftaya kadar kullanıı. ECMO desteği sonlandırılacağı zaman, kardiyak output, pulmoner fonksiyonlar ve venöz oksijen saturasyonu değerlendirilir. Debi yavaş yavaş düşürülür ve hemodinamik stabilite mevcutsa, ECMO durdurulur. Arter ve venöz hat klemplenir. Dekanülasyon için en az yarım saat beklenir. Kan gazları ve diğer hemodinamik bulgular stabil görünüyorsa steril şartlarda dekanülasyon yapilır (9).

ECMO'nun komplikasyonları; kanülasyon bölgesi etrafında kanama, kanulasyon bölgesi distalinde ekstremite iskemisi, böbrek yetmezliği ve sepsistir.

Devamlı yoğun bakım intiyacı gösteren majör sorunlar ve potansiyel hemorajik komplikasyonlar nedeniyle heparin kullanılamayan durumlar kontrendikasyon oluşturur.

\section{Interventional Lung Assist (ILA)-Novalung}

Illk ticari ekstrakorporeal membran ventilatör olan Novalung (Hechingen, Almanya), solunum yetmezliğindeki hastaların kanından aşırı $\mathrm{CO}_{2}$ in uzaklaştırılması için kullanılır. Optimal ventilatör ve farmakolojik desteğe rağmen $\mathrm{CO}_{2}$ eliminasyonunun yeteri kadar başarılamadığı revesibl solunum yetmezliği olan hastalarda gaz değişim desteği sağlar, böylece respiratuar asidozun olumsuz etkilerini giderir (12). Bu amaçla akut respiratuar distres sendromu (ARDS) / akut akciğer zedelenmesi (ALI) hastalarında, KOAH alevlenmelerinde, akciğer transplantasyonu öncesi dönemde kullanılabilir. Sistem, polimetilpenten elyaflardan oluşan bir difüzyon membran aracılığıyla düşük dirençli gaz değişimi sağlar. Bu lifler, basit difüzyon ile oksijen

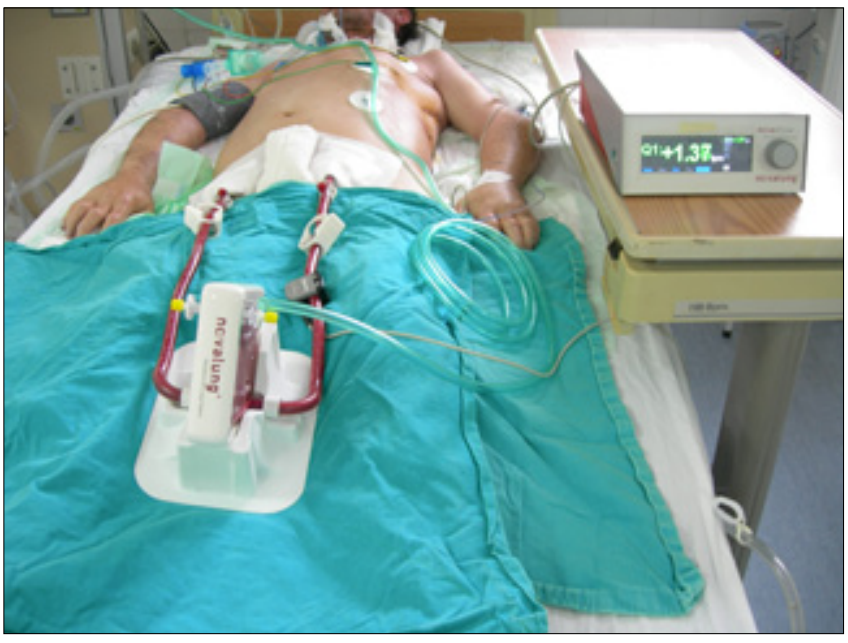

Resim 8. Hastaya bağlanmış halde bulunan Novalung cihazı.

ve $\mathrm{CO}_{2}$ değişimini maksimum gerçekleştirecek, karmaşık bir konfigürasyon halinde dokunmuştur.

Sistem, harici bir pompa yardımı olmadan çalıştırılmak üzere tasarlanmışsa da yüksek kan akımı gerekli ise, aynı zamanda pompa ilave edilebilir. Cihaz, femoral arter ve femoral ven arasında arteriovenöz şant sağlar (Resim 8). Kanülasyon intravenöz heparinizasyon sonrası gerçekleştirilir. Kullanılan arteryel kanül boyutuna ve ortalama sistemik kan basıncına bağlı olarak, 2,5 L/dak (harici bir pompa ile 5,5 L/dak) kan akışı elde edilebilir. Kullanımı için $1 \mathrm{~L} /$ dak altında kan akışı olmamalı, ortalama arteryel basınç $\geq 60, \mathrm{PaO}_{2} /$ $\mathrm{FiO}_{2} \geq 70$ olmalıdır. Spontan ventilasyonun ve stabil kan gazı değerlerinin sağlandığı olgular Novalung'tan ayrilabilirler (8).

Heparin kullanılamayan olgular, septik şok, ciddi kardiak disfonksiyon ve ciddi periferal arteryel okluzyon Novalung kullanımı açısından kontrendikasyon oluşturur (12). En sık görülen komplikasyon, iskemik komplikasyonlardır. Bacak ampütasyonu nadir $(\% 0,9)$ fakat olası bir durumdur.

Olgu serileri Novalung ile arteryel kanda belirgin $\mathrm{CO}_{2}$ düşüşünü ve respiratuar asidozun düzeldiğini göstermektedir.

\section{KAYNAKLAR}

1. Köner Ö. Yoğun bakımda sistemik kan basıncı monitorizasyonu. Türk Yoğun bakım Derneği Dergisi 2006;4:14-7.

3. Scheer B, Perel A, Pfeiffer UJ. Clinical review: complications and risk factors of peripheral arteryel catheters used for haemodynamic monitoring in anaesthesia and intensive care medicine. Crit Care 2002;6:199-204. [CrossRef]

4. Ülger F. Santral venöz kateterizasyon ve monitorizasyon ve komplikasyonları. Türk Yoğun bakım Derneği Dergisi. 2006;4:18-29.

5. American Society of Anesthesiologists Task Force on Central Venous Access, Rupp SM, Apfelbaum JL, Blitt C, 
Caplan RA, Connis RT, et al. Practice guidelines for central venous access: a report by the American Society of Anesthesiologists Task Force on Central Venous Access. Anesthesiology 2012;116:539-73. [CrossRef]

6. McGee DC, Gould MK. Preventing complications of central venous catheterization. N Engl J Med 2003;348:112333. [CrossRef]

7. Frykholm P, Pikwer A, Hammarskjöld F, Larsson AT, Lindgren $S$, Lindwall $R$, et al. Clinical guidelines on central venous catheterisation. Acta Anaesthesiol Scand 2014;58:508-24. [CrossRef]

10. Sarıbülbül O. Açık kalp makinası ekstrakorporeal dolaşım. Kalp ve Damar Cerrahisi. Duran E, ed. Bölüm 75, sayfa 1047-74.

11. Küçükaksu DS. Ventriküler destek sistemleri. Kalp ve Damar Cerrahisi. Paç M, Akçevin A, Aka SA, Büket S, Sarıoğlu T, eds. Bölüm 17, sayfa: 351-416.

12. Çakar N. Ekstrakorporeal akciğer destek sistemleri. Türk Yoğun bakım Derneği Dergisi. 2008;6:45-8. 